\title{
Health-Related Quality of Life Difference between Early Diagnosed and Finished Therapy of Nephrotic Syndrome in Children
}

\author{
Riska Habriel Ruslie ${ }^{1 *}$ (D), Darmadi Darmadi ${ }^{2} \mathbb{D}$, Cennikon Pakpahan $^{3}$ iD \\ ${ }^{1}$ Department of Child Health, Faculty of Medicine, Universitas Prima Indonesia, Medan, Indonesia; ${ }^{2}$ Department of Internal \\ Medicine, Faculty of Medicine, Universitas Sumatera Utara, Medan, Indonesia; ${ }^{3}$ Department of Biomedical Sciences, Faculty \\ of Medicine, Universitas Airlangga, Surabaya, Indonesia
}

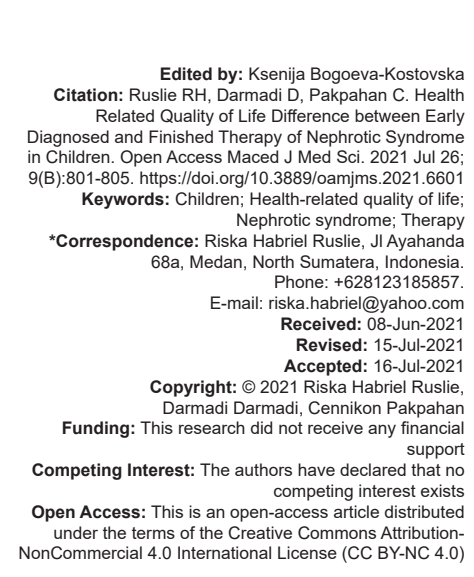

Introduction

Nephrotic syndrome is the most common glomerular disease in children [1], [2], [3]. The prevalence of nephrotic syndrome globally is 1.15$16.9 / 100,000$ children while in the South Asia region is $2-7 / 100,000$ children. In Germany, the incidence of nephrotic syndrome is $1.2-1.8 / 100,000$ children annually, while it is $3-3.5 / 100,000$ children annually in France and 6.48/100,000 children in Japan [4], [5], [6]. Its prevalence in Indonesia is $6 / 100,000$ children with male to female ratio ranges from $2: 1$ to $3: 2$. South Asian and African-American children have higher risk for suffering from nephrotic syndrome compared to European decent [7]. Nephrotic syndrome required a total of 259 million USD for healthcare-related cost between 2006 and 2009 in the USA. Worse complications were associated with longer hospital length of stay and the presence of underlying comorbidities [8].

The clinical outcome of the nephrotic syndrome has improved since the use of prednisone in the 1950s [9]. The management of nephrotic syndrome at present is not only focusing on outcomes of disease but also the burden related to the quality of life [1], [10]. Quality of life is the degree to which a person enjoys the important possibilities of his or her life [11]. When being used in relation with medical conditions, it refers to the wellbeing of an individual affected by disease, disability, or disorder and widely known as healthrelated quality of life (HRQOL) [1], [11]. HRQOL of children with nephrotic syndrome in developed countries is influenced by steroid dependence, steroid resistance, cytotoxic therapy, frequency of relapse, disease severity, socioeconomic status, and duration of illness [11].

Several studies had determined the HRQOL in children with nephrotic syndrome. Shutto et al. in their study reported that children with nephrotic syndrome had lower quality of life for general health and social functioning compared to healthy population. For social functioning, the score was even lower compared to population with two or more chronic diseases. Their study utilized PedsQL 4.0 to measure HRQOL [12]. In the other hand, study comparing HRQOL of children before and after therapy is scarce. Our study aimed to 
determine the difference of HRQOL in children between early diagnosed and finished therapy of nephrotic syndrome.

\section{Patients and Methods}

A cross-sectional study was conducted in Pediatric Nephrology Division, Haji Adam Malik General Hospital, Medan, Indonesia between January and December 2018. Subjects were children aged 1-18 years with nephrotic syndrome in the $1^{\text {st }}$ week of full dose corticosteroid treatment or in the $1^{\text {st }}$ week after finishing therapy. Subjects were divided into 2 groups based on their treatment status. Exclusion criteria were children with glomerular filtration rate $\leq 60 \mathrm{~mL} / \mathrm{min} / 1.73 \mathrm{~m}^{2}$ body surface area or systemic diseases such as malignancy, tuberculosis, severe malnutrition, cardiac disease, liver disease, systemic lupus erythematosus, and Henoch Schonlein purpura. This study was approved by the Institutional Review Board of Universitas Sumatera Utara.

All subjects who fulfilled the inclusion criteria were interviewed to obtain demographical data. Nutritional status was determined based on weight for height for specific gender and age group. Laboratory examination was conducted to determine renal function, albumin level, and cholesterol level. PedsQL 4.0 questionnaire in the Indonesian language was utilized to measure HRQOL of each subject. Higher PedsQL 4.0 score indicates better HRQOL. The difference of HRQOL was analyzed using independent T-test. Statistical calculation was done at $95 \%$ confidence interval and $P$ value of $<0.05$ was considered significant.

\section{Results}

A total of 100 subjects enrolled in this study and divided into two groups equally. Male subjects were dominant compared to female ones with a ratio of $4: 1$ in the early diagnosed group and 7.3:1 in finished therapy group. Mean age of subjects for early diagnosed group and finished therapy group were 5.6 years and 5.3 years, respectively. Most subjects had normal nutritional status. Mean ureum and creatinine levels in both groups were not different. Mean albumin level was higher in finished therapy group while urine albumin to creatinine ratio (UACR) and total cholesterol level was lower in that group (Table 1).

Based on PedsQL 4.0, total HRQOL was improved after treatment administration in children with nephrotic syndrome $(p<0.001)$ (Figure 1).
Table 1: Baseline characteristics of subjects

\begin{tabular}{|c|c|c|c|}
\hline \multirow[t]{2}{*}{ Characteristics } & \multicolumn{2}{|c|}{ Nephrotic syndrome } & \multirow[t]{2}{*}{$p$-value } \\
\hline & Early diagnosed & Finished therapy & \\
\hline Gender, n (\%) & & & 0.275 \\
\hline Male & $40(80)$ & $44(88)$ & \\
\hline Female & $10(20)$ & $6(12)$ & \\
\hline Nutritional status, $\mathrm{n}(\%)$ & & & 0.623 \\
\hline Underweight & $9(18)$ & $6(12)$ & \\
\hline Normal & $36(72)$ & $37(74)$ & \\
\hline Overweight & $5(10)$ & $7(14)$ & \\
\hline Mean age, years (SD) & $5.6(1.44)$ & $5.3(1.08)$ & 0.396 \\
\hline Mean ureum, g/dL (SD) & $23.4(5.23)$ & $23.4(5.35)$ & 0.989 \\
\hline Mean creatinine, g/dL (SD) & $0.7(0.08)$ & $0.6(0.07)$ & 0.230 \\
\hline Mean albumin, g/dL (SD) & $1.7(0.32)$ & $3.0(0.24)$ & $<0.001 *$ \\
\hline Mean UACR, mg/g (SD) & $3.3(0.40)$ & $0.5(0.15)$ & $<0.001 *$ \\
\hline Mean total cholesterol, mg/dL (SD) & $280.5(43.21)$ & $164.7(10.71)$ & $<0.001 *$ \\
\hline
\end{tabular}

Specifically, the improvement was most significant in physical domain $(P=0.002)$, followed by emotional $(p=0.011)$ and social $(p=0.035)$ domains. School domains were not improved significantly after the treatment $(p=0.110)$ (Table 2).

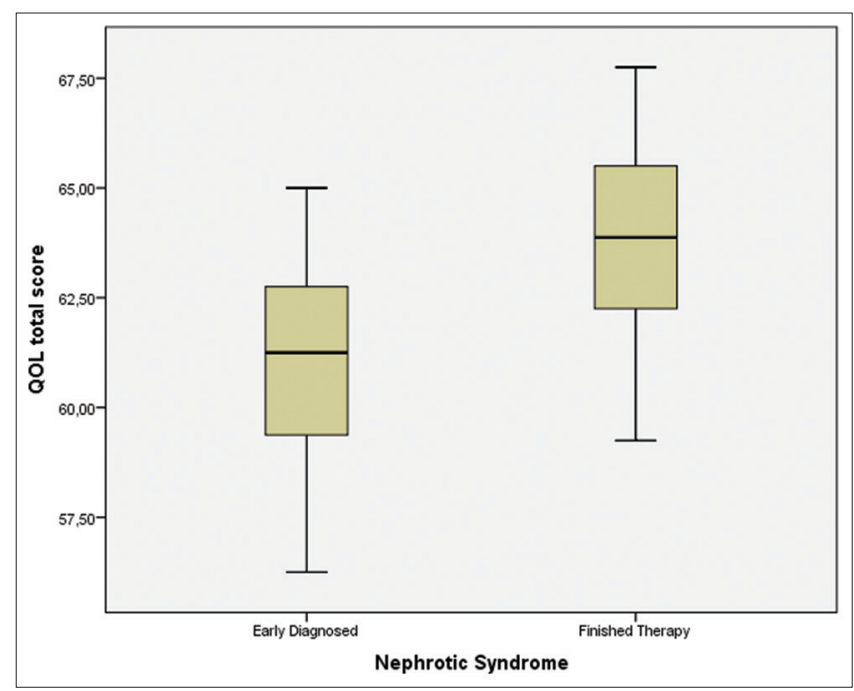

Figure 1: Boxplot diagram representing total score of $H R Q O L$ in children with early diagnosed and finished therapy of nephrotic syndrome

\section{Discussion}

Nephrotic syndrome is a disorder marked by massive proteinuria ( $>40 \mathrm{mg} / \mathrm{m}^{2} / \mathrm{h}$ or urine protein/ creatinine ratio $\geq 200 \mathrm{mg} / \mathrm{mL}$ or $3+$ protein on urine dipstick), hypoalbuminemia $(<2.5 \mathrm{~g} / \mathrm{dL})$, edema, and hypercholesterolemia (>200 mg/dL) [7], [13], [14]. It is a chronic disease with significant morbidities and frequent relapses [2]. The incidence of nephrotic

Table 2: HRQOL difference between early diagnosed and finished therapy groups of children with nephrotic syndrome based on PedsQL 4.0

\begin{tabular}{llll}
\hline Domains & \multicolumn{2}{l}{ Mean score (SD) } & p-value \\
\cline { 2 - 3 } & Early Diagnosed & Finished Therapy & \\
\hline Physical & $62.7(3.22)$ & $67.5(6.11)$ & $0.002^{*}$ \\
Emotional & $59.4(3.14)$ & $61.8(3.10)$ & $0.011^{*}$ \\
Social & $64.4(3.14)$ & $66.4(3.16)$ & $0.035^{*}$ \\
School & $57.5(3.94)$ & $59.2(3.24)$ & 0.110 \\
Total & $61.0(2.14)$ & $63.7(2.42)$ & $<0.001^{*}$ \\
\hline${ }^{*}<0.05$ & & &
\end{tabular}


syndrome is higher in Asian compared to European descents. Median age of patients with nephrotic syndrome in a study from Indonesia was 8.5 years with male predominance at a ratio of $2: 1$ to $3: 2$ [7]. A study by Esezobor et al. found that median age of children with nephrotic syndrome was 7.3 years [15]. Roussel et al. reported a higher mean age which was 11.6 years [2]. The onset of disease is usually preceded by infections such as upper respiratory infection [14]). Mean age of subjects in this study was lower compared to previous literatures. Males were more dominant compared to females with higher ratio (4:1 in early diagnosed group and 7.3:1 in finished therapy group).

Glomerular filtration happens due to interaction of microstructures which are consisted of glomerular basement membrane, fenestrated endothelium, and podocytes. This system is charged and sizespecific, therefore, only several substances may pass through it [14]. Nephrotic syndrome may be caused by glomerular disorders, vasculitides, infections, toxins, malignancy, genetic mutations, and most commonly, unknown [5], [6], [13], [14]. The etiologies disrupt podocyte or glomerular basement membrane and result in disorder of glomerular filtration [5], [6], [14]. This situation makes plasma protein able to pass through slit diaphragm into urine and leads to proteinuria and hypoalbuminemia [5], [6]. Hyperlipidemia is also a marker of nephrotic syndrome. Hyperlipidemia is caused by increased synthesis of cholesterol, triglycerides, and lipoproteins in the liver, hypoalbuminemia (as albumin transports cholesterol in the bloodstream), decreased activity of lipoprotein lipase, and acquired lecithincholesteryl acyltransferase deficiency through urinary loss which prevents the development of HDL [5], [14]. Starling forces underlies the pathophysiology of edema. The loss of a large amount of albumin in the urine leads to hypoalbuminemia and decreased plasma oncotic pressure. This condition results in fluid sequestration in the interstitial compartment which manifested as edema [5], [16].

Corticosteroid is the primary treatment for nephrotic syndrome [5], [6], [8]. It reduces the mortality rate and induces remission in most children with nephrotic syndrome. Corticosteroid treatment consists of full and alternating doses with at least 8 weeks of treatment in total. However, corticosteroid has several side effects including growth impairment, osteoporosis, cataract, weight gain, and behavioral and psychological disturbances [5], [6], [8], [14]. Remission of nephrotic syndrome is marked by urine albumin trace or negative on dipstick or proteinuria $<4 \mathrm{mg} / \mathrm{m}^{3} / \mathrm{h}$ or urinary protein to creatinine ratio $>200 \mathrm{mg} / \mathrm{g}(20 \mathrm{mg} / \mathrm{mmol})$ for 3 consecutive days [6]. Subjects in our study received corticosteroid therapy (prednisone) for 8 weeks in total. After the treatment, clinical improvement was observed from albumin level, UACR, and total cholesterol level.

Fewer than $10 \%$ of children with nephrotic syndrome grow resistance toward steroid and require alternative treatments [2], [6]. Alternative treatments for nephrotic syndrome in children are cyclophosphamide, levamisole, mycophenolate mofetil, cyclosporin, tacrolimus, and rituximab [3], [5], [6], [8]. Even though Asian children have higher incidence rate of nephrotic syndrome, they have less complicated clinical outcomes compared to European children [9]. The rate of treatment resistant was higher in African American and Hispanic children [7]. Overall, the prognosis of nephrotic syndrome is favourable. Only $5 \%$ of patients develop end-stage renal disease [5], [6], [13]. Several complications following nephrotic syndrome are infections such as peritonitis and pneumonia, thromboembolism, kidney injury, and dyslipidemia [4], [6], [8], [14].

Concern regarding $\mathrm{HRQOL}$ is important in applying a comprehensive management to children with nephrotic syndrome [10]. Children with nephrotic syndrome experience physical changing which can be uncomfortable and affect HRQOL. Chronic and abundant treatments with frequent hospitalization also aggravate the decrease of HRQOL. There are several methods for measuring $\mathrm{HRQOL}$ in the pediatric population including PedsQL 4.0, the Patient Reported Outcomes Measurement Information System (PROMIS), the Netherlands Organization for Applied Scientific Research Academical Medical Center Child Quality of Life Questionnaire, and the Child Health and IIIness Profile-Adolescent Edition [10], [17]. The PedsQL Generic Core Scale is used to assess children's and parent's HRQOL based on their perceptions. It is flexible, reliable, and valid in measuring 4 domains which are physical, emotional, social, and school performance [10]. In this study, we used PedsQL 4.0 questionnaire to determine HRQOL in children with early diagnosed and finished therapy nephrotic syndrome. The questionnaire had been translated into the Indonesian language and undergone validity and reliability test.

Gipson et al. reported that children with active nephrotic syndrome had worse scores in several domains of PROMIS such as pain interference, anxiety, fatigue, and mobility compared to those with remission state nephrotic syndrome [17]. A study by Mbanefo et al. showed that HRQOL in children with nephrotic syndrome was negatively affected by the presence of edema, massive proteinuria, steroid resistance, and non-minimal change histology type. Children with those properties had lower HRQOL compared to those who hadn't [11].

Ruth et al. conducted a study to determine the quality of life and psychosocial adjustment in children with steroid-sensitive nephrotic syndrome. They found that social domain of quality of life and psychosocial adjustment were impaired in children with steroidsensitive nephrotic syndrome compared to healthy control. Disease severity and family support played important role in maintaining good quality of life and psychosocial adjustment [18]. HRQOL of children with 
nephrotic syndrome was lower compared to healthy children but was still higher compared to children with other chronic non-renal illness. Among all children with nephrotic syndrome, steroid-resistant ones had the lowest quality of life in all domains. The long duration of illness, higher frequency of relapse, higher cumulative steroid dose, and more abundant medications hampered the quality of life in this study [1].

Agrawal et al. reported that the total quality of life score in children with nephrotic syndrome was higher compared to children with other chronic diseases specifically in physical, emotional, and social domains. However, phenotypes of nephrotic syndrome, age, gender, duration of illness, and steroid resistance did not influence the quality of life of children with nephrotic syndrome in this study [10]. Burden was not only affecting the patients but also their caregivers, especially regarding psychological distress. Esezobor et al. found that $30.8 \%$ of caregivers suffered psychosocial distress. Chronic nature of disease, frequent hospitalization, and frequency of relapse play important role in the severity of psychosocial distress [15]. In contrast, Roussel et al. found that quality of life of children with difficult-to-treat" nephrotic syndrome was still high and close to children without any chronic disease. They also found that disease duration, relapse frequency, and age did not affect quality of life [2].

In our study, the total score for HRQOL differed significantly between children in early diagnosed nephrotic syndrome and childen in finished therapy of nephrotic syndrome (61.0 versus 63.7; $p<0.001)$. This confirmed previous literature than HRQOL would be improved after corticosteroid therapy or remission. Our study's result was also in accordance with majority result from previous studies where physical, emotional, social, and school domains were affected in the early course of disease. Significant improvements were also observed in all domains except school domain. There were several limitations in our study. Crosssectional design and unmatched subjects increased the possibility of confounding factors to influence the HRQOL. We did not analyze the role of confounding factors such as steroid dependence, steroid resistance, cytotoxic therapy, frequency of relapse, disease severity, socioeconomic status, and duration of illness on HRQOL. We also did not stratify subjects based on severity of nephrotic syndrome, which in several literatures might affect HRQOL.

\section{Conclusion}

HRQOL in children with early diagnosed nephrotic syndrome was lower compared to children with finished therapy of nephrotic syndrome. The most significant improvement was observed in physical domain, followed by emotional and social domains. HRQOL in school domain was also improved but not significant.

\section{Acknowledgment}

The authors thanked all of subjects and their families for their cooperation during this study.

\section{References}

1. Eid R, FathyAA, Hamdy N. Health-related quality of life in Egyptian child with nephrotic syndrome. Qual Life Res. 2020;29(8):218596. https://doi.org/10.1007/s11136-020-02438-0 PMid:32016684

2. Roussel A, Delbet J, Micheland L, Deschenes G, Decramer S, Ulinski T. Quality of life in children with severe forms of idiopathic nephrotic syndrome in stable remission-a cross-sectional study. Acta Paediatr. 2019;108(12):2267-73. https://doi.org/10.1111/ apa.14912

PMid:31240744

3. Ruslie RH, Ramayani OR, Darmadi D, Siregar GA. Oxidative stress markers in initial therapy and remission of nephrotic syndrome and serum malondialdehyde level predictor from routine laboratory test. Med Glas (Zenica). 2021;18(1):90-5.

PMid:32815672

4. Franke I, Aydin M, Kurylowicz L, Lopez CE, Ganschow R, Lentze MJ, et al. Clinical course and management of childhood nephrotic syndrome in Germany: A large epidemiological ESPED study. BMC Nephrol. 2019;20(1):45. https://doi. org/10.1186/s12882-019-1233-1

PMid:30732569

5. Downie ML, Gallibois C, Parekh RS, Noone DG. Nephrotic syndrome in infants and children: Pathophysiology and management. Paediatr Int Child Health. 2017;37(4):248-58. https://doi.org/10.1080/20469047.2017.1374003 PMid:28914167

6. Noone DG, lijima K, Parekh R. Idiopathic nephrotic syndrome in children. Lancet. 2018; 392(10141):61-74. https://doi. org/10.1016/s0140-6736(18)30536-1 PMid:29910038

7. Albar H, Bilondatu F. Profile of pediatric nephrotic syndrome in Wahidin Sudirohusodo Hospital, Makassar, Indonesia. Cermin Dunia Kedokteran. 2019;46(3):185-8.

8. Wang C, Yan J, Palmer R, Bost J, Wolf MF, Greenbaum LA. Childhood nephrotic syndrome management and outcome: A single center retrospective analysis. Int J Nephrol. 2017;2017:2029583. https://doi.org/10.1155/2017/2029583

PMid:28326197

9. Banh TH, Hussain-Shamsy N, Patel V, Vasilevska-Ristovska J, Borges $\mathrm{K}$, Sibbald $\mathrm{C}$, et al. Ethnic differences in incidence and outcomes of childhoodnephroticsyndrome. Clin JAmSocNephrol. 2016;11(10):1760-8. https://doi.org/10.2215/cjn.00380116 PMid:27445165

10. Agrawal S, Krishnamurthy S, Naik BN. Assessment of quality of life in children with nephrotic syndrome at a teaching hospital 
in South India. Saudi J Kidney Dis Transpl. 2017;28(3):593-8. https://doi.org/10.4103/1319-2442.206452

PMid:28540898

11. Mbanefo NR, Odetunde Ol, Okafor HU, Oguonu T, Ikefuna AN, Ubesie AC, et al. The clinical parameters affecting the healthrelated quality of life of children with nephrotic syndrome. Arch Nephrol. 2018;1(1):11-8.

12. Shutto $Y$, Yamabe H, Shimada M, Fujita T, Nakamura N. Quality of life in patients with minimal change nephrotic syndrome. ScientificWorldJournal. 2013;2013:124315. https://doi. org/10.1155/2013/124315 PMid:23533341

13. Varner JD, Matory A, Gbadegesin RA. Genetic basis of health disparity in childhood nephrotic syndrome. Am J Kidney Dis. 2018;72 Suppl 1:S22-5. https://doi.org/10.1053/j. ajkd.2018.06.022

PMid:30343718

14. Andolino TP, Reid-Adam J. Nephrotic syndrome. Pediatr Rev. 2015;36(3):117-25; quiz 126, 129.

PMid:25733763
15. Esezobor $\mathrm{Cl}$, Solarin AU, Olagunju AT. Significant burden and psychological distress among caregivers of children with nephrotic syndrome: Across-sectional study. Can J Kidney Health Dis. 2020;7:1-8. https://doi.org/10.1177/2054358119898016 PMid:31949915

16. Ellis D. Pathophysiology, evaluation, and management of edema in childhood nephrotic syndrome. Front Pediatr. 2016;3:111.

PMid:26793696

17. Gipson DS, Selewski DT, Massengill SF, Wickman L, Messer KL, Herreshoff E, et al. Gaining the PROMIS perspective from children with nephrotic syndrome: A Midwest pediatric nephrology consortium study. Health Qual Life Outcomes. 2013;11:30. https://doi.org/10.1186/1477-7525-11-30 PMid:23510630

18. Ruth E, Landolt MA, Neuhaus TJ, Kemper MJ. Health-related quality of life and psychosocial adjustment in steroid-sensitive nephrotic syndrome. J Pediatr. 2004;145(6):778-83. https://doi. org/10.1016/j.jpeds.2004.08.022

PMid:15580200 